\title{
Physical activity among doctors of School of Medicine/University of Sulaimani
}

\author{
Article by Prusha Shwan M. Salih \& Pawan Jamal Mahmud \\ Department of Community and Family Medicine, Iraq \\ Email: Prusha_91@yahoo.com
}

\begin{abstract}
Background: Exercise is also known as physical activity. In simple terms exercise is any movement that works your body at a greater intensity than your usual level of daily activity. Exercise raises your heart rate and works your muscles and is most commonly undertaken to achieve the aim of physical fitness. It offers major health benefits and counselling for it should be integrated into the medical consultation.

Objectives: To estimate the prevalence of physical activity habits among doctors in School of medicine / faculty of medical sciences. Also, to identify the reasons for engagement in physical exercise among the study population and the reasons for not engaging in physical activity. Besides that, to determine whether physicians in the study encourage their patients to be physically active through their advice and lifestyle, and whether they encourage to study sport medicine in medical colleges.

Method : A cross-sectional study was carried out among doctors who are in contact and lecturers of the school of medicine/faculty of medical sciences/university of sulaimani. The questionnaire were collected by visiting their hospitals, departments or branches from March $1^{\text {st }}$ till April $1^{\text {st }}$ and was a self-administered questionnaire and verbal consent was taken. The doctors absolutely voluntarily participated in the study, and obtained information was coded and anonymous. The data of this study was entered and analyzed by using Statistical Package for Social Science (SPSS) version 21.0 software program .

Result : In this study the collected data are 91 , in which $64.8 \%$ are male and $25.2 \%$ are female, and age ranges 29 - 63, with highest response between 35 - 44 age group, and BMI ranged from $<18$ to $>30$ with the highest response from over-weighted group, and among specialty the highest response were among surgeons.

The prevalence of physical activity assessed as $53.8 \%$ and with no significant associations between physical activity with age, gender, marital status and BMI but only specialty shows significant association of $80.8 \%$ of surgeons. There is close prevalence of physical activity between male and female of $52.5 \%$ and $56.25 \%$ respectively, and highest prevalence for age are among 45 and above, and normal and obese BMI groups are of highest in engaging in physical activities and overall $59.2 \%$ do exercise regularly. The most common motivator is improving health $38.8 \%$, and most cited barriers are being busy with family (37.4\%) and being too tired (35.2\%).91.2\% recommend studying sport medicine in medical colleges, and 97.7 counsel their patients for exercising.

Conclusion : Doctors shows good engagement in physical activities. Prevalence of exercise is not related to gender, age ,BMI, marital status but only associated with specialty. Male and female show close prevalence of engagement in physical activities. The regularity of exercise among doctors is not maintained as expected. Most doctors recommend studying Sport medicine in medical colleges. The most common motivator among doctors is improving health, and being busy with family and being tired are the most cited barrier. Being a doctor has affect in not participating in physical activities by many ways. Most doctors counsel their patients about exercise.
\end{abstract}


South American Journal of Public Health

Special Edition May 2016

\section{Introduction}

\subsection{Definition}

Exercise is physical activity that is planned, structured, and repetitive for the purpose of conditioning any part of the body. Exercise is used to improve health, maintain fitness and is important as a means of physical rehabilitation ${ }^{[1]}$

Regular Exercise is any planned physical activity (e.g., brisk walking, aerobics, jogging, bicycling, swimming, rowing, etc.) performed to increase physical fitness. Such activity should be performed 3 to 5 times per week for 20-60 minutes per session. Exercise does not have to be painful to be effective but should be done at a level that increases your breathing rate and causes you to break a sweat. ${ }^{[2]}$

\subsection{History of exercise}

The benefits of exercise have been known since antiquity. The history of exercise dates back to the birth of humankind, though earlier humans might not have realized that they were indeed exercising, when running for their lives from wooly mammoths. In and around 400 BC, Hippocrates famously mentioned about exercise, "If we could give every individual the right amount of nourishment and exercise, not too little and not too much, we would have found the safest way to health." Being a time of great ideas and new thought, people seriously started to study the importance and relevance of physical exercise, and its effects on human health. Hippocrates's same thoughts were shared by other famous thinkers, Cornelius Celsus and Galen, a few centuries later. ${ }^{[3]}$ Marcus Cicero, around 65 BC, stated: "It is exercise alone that supports the spirits, and keeps the mind in vigor." ${ }^{[4]}$ However, the link between physical health and exercise (or lack of it) was only discovered in 1949 and reported in 1953 by a team led by Jerry Morris (was a Scottish epidemiologist who established the importance of physical activity in preventing cardiovascular disease. $)^{[5]}$

The rise of media, especially television, in the latter half of 19th century, also had done its part in spreading the importance of remaining fit. The internet revolution in the last decade before 2000 had made people even more empowered and it brought them at arms' length with innumerable resources pertaining to workouts, fitness, and health. And soon the wheels of history of exercises were undergoing a redefinition once again. ${ }^{[4]}$

\subsection{Types of exercise}

Generally there are three categories of exercise :

- Aerobic exercises, such as cycling, swimming, walking, skipping rope, rowing, running, hiking or playing tennis, focus on increasing cardiovascular endurance. ${ }^{[6]}$

- Anaerobic exercises, such as weight training, functional training, eccentric training or sprinting and high-intensity interval training, increase short-term muscle strength. ${ }^{[7]}$

- Flexibility exercises, such as stretching, improve the range of motion of muscles and joints. ${ }^{[8]}$

\subsection{Benefits of exercise}

- Helps control your weight and prevent obesity, thus gives body a good appearance and prevent complications of obesity. ${ }^{[9]}$

- Frequent and regular physical exercise boosts the immune system. ${ }^{[9]}$

- helps prevent the "diseases of affluence" such as heart disease, cardiovascular disease, Type 2 diabetes . ${ }^{[9][10]}$

- improves mental health, helps prevent depression, helps to promote or maintain positive self-esteem, and can even augment an individual's sex appeal or body image, which is also found to be linked with higher levels of self-esteem. ${ }^{[1]}$

- Strengthens muscles, bones, and joints. Also Increases bone density, which

- helps prevent osteoporosis ${ }^{[11]}$ 
- exercise generally improves sleep for most people, and helps sleep disorders such as insomnia. ${ }^{[12]}$

- can be fun and socializing, can be a fun way to spend some time. It gives you a chance to unwind, enjoy the outdoors or simply engage in activities, help you connect with family or friends in a fun social setting. ${ }^{[12]}$

\subsection{Categories of exercise}

\section{Strengthening exercise}

Strengthening exercise increases muscle strength and mass, bone strength, and the body's metabolism. It can help attain and maintain proper weight and improve body image and selfesteem. such as walking, running, and climbing stairs. Strengthening exercises increase muscle strength by putting more strain on a muscle than it is normally accustomed to receiving. This increased load stimulates the growth of proteins inside each muscle cell that allow the muscle as a whole to contract. ${ }^{[13]}$

\section{Isometric exercise}

During isometric exercises, muscles contract. However, there is no motion in the affected joints. The muscle fibers maintain a constant length throughout the entire contraction. The exercises usually are performed against an immovable surface or object such as pressing one's hand against a wall. This kind of training can provide a relatively quick and convenient method for overloading and strengthening muscles without any special equipment and with little chance of injury. ${ }^{[13]}$

\section{Isotonic exercise}

Isotonic exercise differs from isometric exercise in that there is movement of a joint during the muscle contraction. A classic example of an isotonic exercise is weight training with dumbbells and barbells. As the weight is lifted throughout the range of motion, the muscle shortens and lengthens. These would include chin-ups, push-ups, and sit-ups, all of which use body weight as the resistance force. ${ }^{[13]}$

\section{Isokinetic exercise}

Isokinetic exercise utilizes machines that control the speed of contraction within the range of motion.. It provides muscular overload at a constant preset speed while a muscle mobilizes its force through the full range of motion. For example, an isokinetic stationary bicycle. Machines known as Cybex and Biodex provide isokinetic results; they generally are used by physical therapists. ${ }^{[13]}$

\section{6 effects of excessive exercise}

Exercise burnout may occur if an exercise program is not varied and adequate rest periods are not taken between exercise sessions. Muscle, joint, and cardiac disorders have been noted among people who exercise. However, they often have had preexisting or underlying illnesses. ${ }^{[14]}$

Improper warm up can lead to muscle strains. Overexertion without enough time between exercise sessions to recuperate also can lead to muscle strains, resulting in inactivity due to pain or Rhabdomyolysis. Stress fractures also are a possibility if activities are strenuous over long periods without proper rest. ${ }^{[14]}$

Inappropriate exercise can do more harm than good, with the definition of "inappropriate" varying according to the individual. For many activities, especially running and cycling, there are significant injuries that occur with poorly regimented exercise schedules. Injuries from accidents also remain a major concern ${ }^{[15]}$ whereas the effects of increased exposure to air pollution seem only a minor concern. ${ }^{[16]}$

Too much exercise can also cause a female to miss her period, a symptom known as amenorrhea. ${ }^{[17]}$

Extreme exercise such as marathons may permanently damage the heart and trigger rhythm abnormalities, as 'upper limit' for heart health is a maximum of an hour a day - after which there is little benefit to the individual. 
Activities such as marathons, iron man distance triathlons, and very long distance bicycle races may cause structural changes to the heart and large arteries, leading to lasting injury. ${ }^{[18]}$

Although exercise is good for your health, extreme exercise may be physically addicting, The scientists who conducted the study reason that if excessive exercise is addicting, then maybe, to feel good, addicts could take moderate exercise instead of drugs. The findings also shed light on the potentially fatal eating disorder called anorexia athletica, in which exercise undertaken to shed pounds becomes as compulsive as taking drugs, resulting in even greater weight loss. ${ }^{[19]}$

Stopping excessive exercise suddenly can also create a change in mood. Feelings of depression and agitation can occur when withdrawal from the natural endorphins produced by exercise occurs. ${ }^{[20]}$

\subsection{The objectives of this study}

1. To estimate the prevalence of physical activity among Sulaimani Medical college doctors .

2. To identify the reasons for engagement in physical exercise among the study population, and the reasons for not engaging in physical activity.

3. To determine whether physicians in the study encourage their patients to be physically active through their advice and lifestyle, and to know whether they encourage to study sport medicine in medical colleges .

\section{Methodology}

\subsection{Setting of the study}

147 physicians who are related to College of Medicine in University of Sulaimani.

\subsection{Study design}

This is a descriptive study. It is a questionnaire- based cross sectional analysis. Through survey among 147 physicians who are related to College of Medicine of University of Sulaimani, from March $1^{\text {st }}$ till April $1^{\text {st }}$.

\subsection{Study and Sampling}

The study were among 147 physicians who are in contact and lecturers with Faculty of medicine , but excluding those physicians who have no contact with the faculty of medicine.

The data collecting was by survey, and questionnaire was based on necessary questions those need to be answered for this study .

The proposal was approved by the department of community and family medicine of faculty of medicine. After explaining the content of the questionnaire form to the participants, verbal informed consent was obtained. The Physicians absolutely voluntarily participated in the study, participant's privacy was respected, and all obtained information was coded and anonymous.

The questionnaire consists of three parts : demographic information, part to those who exercise, another part to those who do not exercise .

The questionnaire were collected among the numbered physicians by visiting their hospitals, departments or branches from March $1^{\text {st }}$ till April $1^{\text {st }}$ between 8:30 am to 2:00 pm.

The data of this study was entered and analyzed by using Statistical Package for Social Science (SPSS) version 21.0 software program by descriptive frequency and Chi square and Fisher exact test the results achieved.

\section{Results}

The answered surveys were 91 out of doctors as 39 didn't accept filling the survey, and 17 couldn't be reached as they were travelling or didn't visit college and those hospitals during that month or hours of our visiting.

Among 91 collected data there are 32 female and 59 male physicians are participated. 
Table (1) Socio-demographic characteristics of the participated physicians:

\begin{tabular}{|l|l|l|}
\hline Variable & No. & $\mathbf{\%}$ \\
\hline Gender & & \\
Male & 59 & 64.8 \\
Female & 32 & 35.2 \\
\hline Age & & \\
$25-34$ y & 9 & 9.9 \\
$35-44$ y & 38 & 41.8 \\
$45-54$ y & 34 & 37.4 \\
$\geq 55$ & 10 & 11.0 \\
\hline Marital status & & \\
Single & 13 & 14.3 \\
Married & 78 & 85.7 \\
\hline Body Mass Index (BMI) & & \\
< 18.5 (Underweight) & 2 & 2.2 \\
18.5-24.9 (Normal) & 33 & 36.3 \\
25-29.9 (Overweight) & 42 & 46.2 \\
$\geq 30$ (Obese) & 14 & 15.4 \\
\hline Specialty & & \\
Medicine & 20 & 22.0 \\
Surgery & 26 & 28.6 \\
Community Medicine & 3 & 3.3 \\
Pediatrics & 18 & 19.8 \\
Obstetrics/ Gynecology & 11 & 12.1 \\
Forensic Medicine & 2 & 2.2 \\
Pharmacology +Microbiology & 6 & 6.6 \\
Physiology + Histology + Pathology & 5 & 5.5 \\
\hline
\end{tabular}

Table (2): Frequency and prevalence of physical activity among the physicians

\begin{tabular}{|l|l|l|}
\hline Doing exercise & Frequency & Percent \\
\hline Yes & 49 & 53.8 \\
No & 42 & 46.2 \\
Total & 91 & 100.0 \\
\hline
\end{tabular}

Table (3): Number and Prevalence and association of Female and Male doing exercise

\begin{tabular}{|l|l|l|l|c|}
\hline \multirow{2}{*}{} & \multicolumn{2}{|l|}{ Exercise } & Total & \multirow{2}{*}{ P- value $=0.735$} \\
\cline { 2 - 3 } Female & 18 & 14 & 32 & Df $=1$ \\
Male & 31 & 28 & 59 & \\
Total & 49 & 42 & 91 & \\
\hline & \multicolumn{2}{|l|}{ Active } & & \\
\cline { 2 - 3 } & No. & $\%$ & & \\
\hline Female & 18 & 56.25 & & \\
Male & 31 & 52.5 & & \\
Total & 49 & & & \\
\hline
\end{tabular}


South American Journal of Public Health

Special Edition May 2016

Table (4) association between age and exercise

\begin{tabular}{|c|l|l|l|l|}
\hline \multirow{2}{*}{ Age } & \multicolumn{2}{|c|}{ Exercise } & \multirow{2}{*}{ Total } & \\
\cline { 2 - 3 } $25-34 \mathrm{y}$ & \multicolumn{1}{|c|}{ Yes } & No & & \multirow{2}{*}{ P-value $=0.206$} \\
\cline { 2 - 3 } $35-44 \mathrm{y}$ & $17(44.4 \%)$ & 5 & 9 & Df $=2$ \\
$>45$ & $28(63.6 \%)$ & 21 & 38 & \\
Total & 49 & 16 & 44 & \\
\hline
\end{tabular}

Table (5) association between marital status and exercise

\begin{tabular}{|c|c|c|c|c|}
\hline \multirow{2}{*}{ Marital status } & \multicolumn{2}{|c|}{ Exercise } & \multirow{2}{*}{ Total } & \multirow{2}{*}{ P-value $=0.548$} \\
\cline { 2 - 3 } & Yes & No & & Df $=1$ \\
Single & $8(61.5 \%)$ & 5 & 13 & \\
Married & $41(52.5 \%)$ & 37 & 78 & \\
Total & 49 & 42 & 91 & \\
\hline
\end{tabular}

Table (6) : association between BMI and physical activity among physicians $[\mathrm{P}-$ value $=0.285$ and Df $=3$ ]

\begin{tabular}{|l|c|c|c|}
\hline \multirow{2}{*}{ BMI } & \multicolumn{2}{|c|}{ exercise } & \multirow{2}{*}{ Total } \\
\cline { 2 - 3 } & Yes & No & \\
\hline 18.5 (Underweight) & 1 & 1 & 2 \\
$18.5-24.9$ (Normal) & 21 & 12 & 33 \\
25 - 29.9 ( Overweight) & 18 & 24 & 42 \\
$>=30$ (Obese) & 9 & 5 & 14 \\
Total & 49 & 42 & 91 \\
\hline BMI & \multicolumn{2}{|c|}{ Yes } & \\
\cline { 2 - 3 } & Number & \% & \\
\hline$<18.5$ (Underweight) & 1 & 50 & \\
18.5 - 24.9 (Normal) & 21 & 63.7 & \\
25 - 29.9 ( Overweight) & 18 & 42.8 & \\
$>=30$ (Obese) & 9 & 64 & \\
Total & 49 & & \\
\hline BMI & \multicolumn{2}{|c|}{ No } \\
\cline { 2 - 3 } & Number & \% & \\
\hline$<18.5$ (Underweight) & 1 & 50 & \\
18.5 - 24.9 (Normal) & 12 & 36.3 & \\
25 - 29.9 ( Overweight) & 24 & 47.2 & \\
$>=30$ (Obese) & 5 & 36 & \\
Total & 42 & \\
\hline
\end{tabular}

Table (7) : Association between specialty and exercise [ $\mathrm{P}$-value $=0.012, \mathrm{df}=10$ ]

\begin{tabular}{|l|c|c|c|}
\hline \multirow{2}{*}{ Specialty } & \multicolumn{2}{|c|}{ Exercise } & \multirow{2}{*}{ Total } \\
\cline { 2 - 3 } & Yes & No & \\
\hline Medicine & $8(40 \%)$ & 12 & 20 \\
Surgery & $21(80.8 \%)$ & 5 & 26 \\
Community medicine & $2(66.6 \%)$ & 1 & 3 \\
Pediatrics & $10(50 \%)$ & 10 & 20 \\
Obstetrics & $3(33.3 \%)$ & 6 & 9 \\
Physiology + Microbiology + & $3(42.8)$ & 4 & 7 \\
Pharmacology & & & \\
Pathology + Histology & $1(25 \%)$ & 3 & 4 \\
Forensic med. & $1(50 \%)$ & 1 & 2 \\
\hline
\end{tabular}




\begin{tabular}{|l|l|l|l|}
\hline Total & 49 & 42 & 91 \\
\hline
\end{tabular}

Table (8): knowledge about regularity of exercise among doctor who exercise

\begin{tabular}{|l|c|c|c|}
\hline & Frequency & Percent & Cumulative Percent \\
\hline Regular & 29 & 59.2 & 59.2 \\
Irregular & 20 & 40.8 & 100.0 \\
Total & 49 & 100.0 & \\
\hline
\end{tabular}

Table (9): Characteristics of exercise among the study physicians

\begin{tabular}{|l|l|l|}
\hline Time & Frequency & Valid Percent \\
\hline Childhood & 10 & 27.8 \\
\hline Money spent & Frequency & Valid Percent \\
\hline 0 & 33 & 67.3 \\
$1-25000$ & 7 & 14.3 \\
$26000-50000$ & 2 & 4.1 \\
$51000-100000$ & 6 & 12.2 \\
more than 100000 & 1 & 2.0 \\
0 & 33 & 67.3 \\
\hline Place & Frequency & Valid Percent \\
\hline Home & 32 & 65.3 \\
Gym & 1 & 2.0 \\
Outside & 10 & 20.4 \\
Home and gym & 3 & 6.1 \\
Home and outside & 3 & 6.1 \\
\hline Days per week & Frequency & Valid Percent \\
\hline 1 day & 3 & 6.1 \\
2 days & 14 & 28.6 \\
3 days & 13 & 26.5 \\
4 days & 7 & 14.3 \\
5 days & 4 & 8.2 \\
6 days & 2 & 4.1 \\
7 days & 6 & 12.2 \\
\hline Time spent on exercise per day & Frequency & Valid Percent \\
\hline 5-20 minute & 9 & 18.4 \\
more than 20 minute & 40 & 81.6 \\
5-20 minute & 9 & 18.4 \\
\hline
\end{tabular}

Table (10): Purposes behind exercise among doctors

\begin{tabular}{|l|l|}
\hline & \multicolumn{1}{|c|}{ Percent } \\
\hline & \\
Improve health & 38.8 \\
For fun & 4.1 \\
For improving both health and & 24.4 \\
appearance & \\
Multipurpose & 28.6 \\
Others & 4.1 \\
Total & 100.0 \\
\hline
\end{tabular}

Table (11): Achievement of the purposes with exercise

\begin{tabular}{|l|l|l|}
\hline & Frequency & Valid Percent \\
\hline Yes & 25 & 51.0 \\
Partially & 18 & 36.7 \\
No & 6 & 12.2 \\
\hline
\end{tabular}


South American Journal of Public Health

Special Edition May 2016

\begin{tabular}{l|l|l} 
Total & 49 & 100.0
\end{tabular}

Table (12) : Types of exercise which doctors engaged with

\begin{tabular}{|l|l|l|}
\hline & Frequency & Valid Percent \\
\hline Walking & 7 & 14.3 \\
weight lifting & 2 & 4.1 \\
Swimming & 6 & 12.2 \\
biking machine/stationary bike & 4 & 8.2 \\
Treadmill & 3 & 6.1 \\
walking and treadmill & 4 & 8.1 \\
walking and jogging & 7 & 14.3 \\
multiple type of exercise & 16 & 32.7 \\
\hline
\end{tabular}

Table (13): Quitting of exercise among doctors

\begin{tabular}{|c|l|l|}
\hline Exercised but quitted & Frequency & Valid Percent \\
\hline Yes & 32 & 80.0 \\
No & 8 & 20.0 \\
& 40 & 100.0 \\
\hline When & & \\
\hline month - 1 year ago & 5 & Valid Percent \\
2 - 4 years ago & 9 & 16.1 \\
> 5 years ago & 17 & 29.0 \\
Total & 31 & 54.8 \\
\hline Being a doctor has affect in & Frequency & 100.0 \\
quitting exercise & & Valid Percent \\
\hline Yes & 24 & 61.5 \\
No & 15 & 38.5 \\
Total & 39 & 100.0 \\
\hline
\end{tabular}

Table (14): Reasons behind not engaging with exercise

\begin{tabular}{|l|l|l|}
\hline Reasons & No. & Percent \\
\hline Too tired & 32 & $35.2 \%$ \\
Satisfy with their look & 13 & $14.3 \%$ \\
Afraid of being injured & 8 & $8.8 \%$ \\
Busy with family & 34 & $37.4 \%$ \\
Lack a save place & 28 & $30.8 \%$ \\
Bad weather & 24 & $26.4 \%$ \\
Need too much to learn & 16 & $17.6 \%$ \\
Feel embrassed & 9 & $9.9 \%$ \\
Have health problem & 4 & $4.4 \%$ \\
Have no one to exercise with & 17 & $18.7 \%$ \\
Think gym membership is expensive & 0 & $0 \%$ \\
\hline
\end{tabular}

Table (15): Frequency and prevalence of encouragement of doctor to patients to exercise

\begin{tabular}{|l|c|c|c|}
\hline & Frequency & Valid Percent & $\begin{array}{l}\text { Cumulative } \\
\text { Percent }\end{array}$ \\
\hline Never & 2 & 2.3 & 2.3 \\
Sometimes & 35 & 40.2 & 42.5 \\
Always & 50 & 57.5 & 100.0 \\
Total & & 100.0 & \\
\hline
\end{tabular}

Table (16): Encouragement of physicians about studying sport medicine in medical colleges 


\begin{tabular}{|c|l|l|}
\hline Encourage & Frequency & Percent \\
\hline Yes & 83 & 91.2 \\
No & 8 & 8.8 \\
Total & 91 & 100.0 \\
\hline
\end{tabular}

\section{Discussion}

\subsection{Socio-demographic characteristic of the doctors:}

From the results the socio-demographic characteristics of the participants in this study in which among 91 doctors which participated ( $64.8 \%)$ were male and $(35.2 \%)$ were female and according to the results The frequency of exercise among participated doctors is 49 out of 91 are doing exercise which is prevalence of $53.8 \%$. In which this is much lower rate than the prevalence of exercise among students in same college which by a research done among prevalence of exercise among students in college of medicine of Sulaimani university which was of prevalence of $72.1 \%{ }^{[21]}$ and this due to lack of time and busy with family and being tired at work in Physicians' life, but hopefully the rate was more than the study which was done among Bahraini doctors which $29.7 \%$ are active ${ }^{[22]}$, and the study which is done among Saskatoon physicians which only $30 \%$ of them were active. ${ }^{[23]}$ and it was also higher than the level among primary care physicians in Riyadh city who had a level of activity of $23.5 \%{ }^{[24]}$, this may be due to developing of lifestyle.

The gender engagement in exercise , 52.5\% are male and $56.25 \%$ are female and this indicate that females are slightly have active rate than males in engaging in physical activities , although the association between gender and exercise is not significant which is confirmed by Chi square test of P-value $=0.735$, and this result shows opposite to a study done on Bahraini physicians about physical activity which is $44.3 \%$ for male and $18.2 \%$ for female ${ }^{[22]}$, and fortunately it is a good news that our female physicians are active as males and this result is close to the study done in Saskatoon/Canada which there was no significant difference by age in doing exercise, which $30 \%$ male and $27 \%$ female ${ }^{[23]}$.

The age of the participants ranges from 29 to 63 years of age with the highest percentage of participant are between $35-44$ years of age, highest percentage for engaging in physical activities are among 45 years and above which the result is same as done among Bahraini Physicians which $>44$ has highest percentage $(54.5 \%)^{[22]}$, but according to the fisher exact test the association between exercise and age is not significant which there is no high difference between ages engaged in physical activities in this study, which is confirmed by P-value = 0.331 .

About marital status of those who participated, according to the results the association between marital status and exercise is not significant which this confirmed by Chi-square test of $\mathrm{P}$ - value $=0.548$.

By BMI (Body mass index) of participant which are those who over-weighted are the highest rate participants in the study (46.2\%). According to the results the association between BMI and exercise is not significant this confirmed by Fisher exact test of P-value $=0.285$, despite that the normal ranged and obese group have the highest rate among those who are engaged in exercise and this confusing result among obese group may be related to either imbalance in diet, irregularity in exercise or not being honest in answering the survey.

According to the results of specialty of the participated doctors, it can be mentioned the association between specialty and exercise is significant and this is confirmed by Fisher exact test of $\mathrm{P}$ value $=0.012$ which is less than 0.05 , which surgeons have the highest percentage in engaging in exercise.

\subsection{Regularity of exercise among doctors who exercise}

In this study about knowledge and caring about regularity of exercise among doctors who exercise, it shows that among those who exercise only 59.2\% do regular exercise which is should be performed 3 to 5 times per week for 20-60 minutes per session, which this 
percentage is lower than the study which is done among physicians of Minnesota that $65.6 \%$ do regular exercise ${ }^{[25]}$, and the reason mostly because of low knowledge and less caring about regularity of exercise among doctors, but this study also shows that $91.2 \%$ of the physicians encourage to study sport medicine in medical colleges for medical students to be more informed about importance of regularity of exercise.

\subsection{Characteristics, Patterns and purposes of exercise among doctors}

The time since when doctors started exercise is of highest percentage in during childhood $(27.8 \%)$ and recently $(27.8 \%)$, and place where they do physical activities highest percentage is Home (65.3) while Gym is of lowest (2.0) and it can be also mentioned that $(67.3 \%)$ of them will not spend money on exercise , this may be due to lack of time among physicians to go to gym and sport shop centers.

From this study it is obvious that $28.6 \%$ of doctors do exercise 2 days per week while $4.1 \%$ is of 6 days per week, on the other hand $12.2 \%$ do exercise every day.

According to this study the most common motivator of exercise among doctor is to improve health only $(38.8 \%)$, improve both health and appearance $(24.4 \%)$ and $28.6 \%$ for multi-purposes including stress relieving while the fun side of exercise if mostly neglected which is $4.1 \%$. and the continuity of their exercise is because $51 \%$ of them totally achieve their purposes by exercise , $36.7 \%$ partially achieve , but only $12.2 \%$ of them do not achieve their purposes.

About types of exercise which doctors mostly do , 32.7\% do multiple types of exercise and do not stick to one type , among them 4.1 do weight lifting , 12.2 do swimming, while only $2 \%$ do yoga.

\subsection{Reasons behind physical inactivity among doctors}

The results shows that $46.2 \%$ of the participated doctors do not exercise which is mostly related to being busy with family $(37.4 \%)$, too tired $(35.2 \%)$ and lack a save place $(30.8 \%)$ and least goes to gym being expensive $(0 \%)$.

Among doctors who do not exercise $80 \%$ were exercising before but quitted, in which $16.1 \%$ were 1 month - year ago, while $54.8 \%$ were more than 5 years ago and the rest were in between $2-4$ years ago, and $61.5 \%$ mentioned being doctor has affect in not doing exercise by many ways.

\subsection{Physicians counseling for their patients}

Even though the prevalence of doctors who do not exercise is $46.2 \%$, but the results shows that doctors who counsel their patients about exercise are 97.7\% ( 57.5\% of doctors Always do , $40.2 \%$ Sometimes do) and $2.3 \%$ Never prescribe exercise, which is close to the percentage of Estonian doctors who $94 \%$ counsel patients about exercise ${ }^{[26]}$, and this is because of increasing updating and awareness of physicians about importance of exercise for their patients and .

\section{Conclusion \& recommendations}

\section{Conclusions}

1. Physicians shows good engagement in physical activities and of higher prevalence than Bahrain, Riyadh and Saskatoon but lower percentage than their medical students of their faculties.

2. Prevalence of exercise is not related to gender, age ,BMI, marital status but only associated with specialty.

3. Male and female physicians shows close prevalence of engagement in physical activities.

4. The regularity of exercise among doctors is not maintained as expected.

5. Most doctors recommend studying Sport medicine in medical colleges. 
6. The most common motivator among doctors is improving health, and being busy with family and being tired are the most cited barrier for not participating in physical activities.

7. most physicians who quitted exercise admit that being a doctor has affect in not participating in physical activities by many ways.

8. Most doctors counsel their patients about exercise.

\section{Recommendations}

1. Doctors are one of the main role models for the community , the more they exercise and encourage to exercise, the more the community will also do, so they should do exercise in public places.

2. There should be monthly seminars and workshops between doctors and general people to encourage them to exercise.

3. Sport medicine should be put as a subject to be studied in medical colleges, for future doctors to be informed about importance of exercise.

4. Government should provide more special centers and special parks for exercise, so that doctors and general people meet and exercise.

\section{References}

[1.] Al-Shahri M Z, Al-Almaei SM.(1998). Promotion of physical exercise by primary health care physicians in Riyadh City. Saudi Med J; 19:67-69. Riyadh.

[2.] Buman, M. P. and King, A. C., (2010), "Exercise as a Treatment to Enhance Sleep", American Journal of Lifestyle Medicine.

[3.] Dr James O'Keefe, 2012,' Excess exercise hurts the heart”. Saint Luke's Hospital of Kansas City. U.S.

[4.] de Vos, N., Singh, N., Ross, D., Stavrinos, T., et al. 2005. Optimal Load for Increasing Muscle Power During Explosive Resistance Training in Older Adults. The Journals of Gerontology, 60A(5), 638-647.

[5.] "Exercise and Physical Fitness." MedlinePlus.

http://www.nlm.nih.gov/medlineplus/exerciseandphysicalfitness.html. accessed on 4th , march , 2013 at 5:00 p.m.

[6.] Frank Lloyd, Wright Blvd . Scottsdale .

http://www.personalpowertraining.net/Articles/history_of_exercise.htm accessed on 22th Feb. 2013 at 7:30 P.M.

[7.] Hu., F., Manson, J., Stampfer, M., Graham, C., et al. (2001). Diet, lifestyle, and the risk of type 2 diabetes mellitus in women. The New England Journal of Medicine, 345(11), 790-797.

[8.] Hensrud DD, Sprafka J M, Connett J, Leon AS. (1992), Physical activity in Minnesota physicians , Division of Preventive Medicine, Mayo Clinic, Rochester, Minnesota.

[9.] Joris Aertsens, Bas de Geus, Grégory Vandenbulcke, Bart Degraeuwe, Steven Broekx, Leo De Nocker, Inge Liekens, Inge Mayeres, Romain Meeusen, Isabelle Thomas, Rudi Torfs, Hanny Willems, Luc Int Panis (2010). "Commuting by bike in Belgium, the costs of minor accidents". Accident Analysis and Prevention 42 (6): 2149-2157.

[10.] Jacobs, L; Nawrot, Tim S; De Geus, Bas; Meeusen, Romain; Degraeuwe, Bart; Bernard, Alfred; Sughis, Muhammad; Nemery, Benoit et al. (Oct 2010). "Subclinical responses in healthy cyclists briefly exposed to traffic-related air pollution". Environmental Health 9 (64): 64.

[11.] Julia Berry; Anne Bradley; Hillery Magness. "Amenorrhea". The Female Athlete Triad. University of Oregon, Department of Human Physiology.

[12.] Kuper, Simon, (2009), "The man who invented exercise". Financial Times. http://www.ft.com/cms/s/2/e6ff90ea-9da2-11de-9f4a-00144feabdc0.html accessed on 23th Feb. 2013 at 6:20 P.M.

[13.] Leon Hammer, (2011). Stopping Long-Term Strenuous Exercise Suddenly: An Epidemic Treated with Chinese Herbal Medicine, Chinese Medicine Times - Volume 6 Issue 1. China. 
South American Journal of Public Health Special Edition May 2016

[14.] Marcus, B. H., Selby, V. C., Niaura, R. S., \& Rossi, J. S. (1992). Self-efficacy and the stages of exercise behavior change. Research Quarterly for Exercise and Sport, 63, 60-66.

[15.] Medifast Exercise Guide. 2007: Medifast, Inc. Owings Mills, Maryland.

http://www.medifastmedia.com/med/docs/exercise_guide.pdf accessed on $28^{\text {th }}$ Feb 2013 at 11:50 P.M.

[16.] Mayo Foundation for Medical Education and Research (MFMER), July 23, 2011.

http://www.mayoclinic.com/health/exercise/HQ01676/NSECTIONGROUP=2 accessed on $1^{\text {st }}$ March, 2013 at 10:40 P.M.

[17.] O'Connor, D., Crowe, M., Spinks, W. 2005. Effects of static stretching on leg capacity during cycling. Turin, 46(1), 52-56.

[18.] Paul H. Gaertner; Whitmer B. Firor, ; Lindsay Edouard,(1991), Physical inactivity among physicians in Saskatoon, Saskatoon/Canada.

[19.] Robin B. Kanarek, Kristen E. D'Anci, Nicole Jurdak, Wendy Foulds Mathes, (2009). Running and addiction. Behavioral Neuroscience, Vol 123(4), 905-912 .U.S.

[20.] Stefan S. du Plessis, (2011), Division of Medical Physiology, Stellenbosch University, Tygerberg, South Africa , Science Journal 3, 105-113.

[21.] Stampfer, M. J.; Hu, F. B.; Manson, J. E.; Rimm, E. B.; Willett, W. C. (2000). "Primary Prevention of Coronary Heart Disease in Women through Diet and Lifestyle". New England Journal of Medicine 343 (1): 16-22.

[22.] Shilan Othman, Luna Ako, Kazhaw Mohammed, Shilan Ali,(2012), "Prevalence of exercise among students of School of medicine", university of Sulaimani, Kurdistan/Iraq.

[23.] Samia Bahram, Basim Abbas, Jalal Kamal, Ebtisam Fakhro, (June 2003), Leisure -Time Physical Activity Habits Among Bahraini Physicians, Vol.25, No. 2, Bahrain Medical Bulleti.

[24.] Suija et al.,(2010).Physical activity of Estonian family doctors and their counselling for a healthy lifestyle, Department of Polyclinic and Family Medicine, University of Tartu, Tartu, Estonia.

[25.] Wilmore, J., Knuttgen, H. 2003. Aerobic Exercise and Endurance Improving Fitness for Health Benefits. The Physician and Sports medicine, 31(5).

[25.] Zubia Veqar, M Ejaz Hussain ,(2012), Sleep quality improvement and Exercise , Centre for physiotherapy and rehabilitation sciences, New Delhi / India. 